\title{
NEAR -SOURCE PULSE-LIKE SEISMIC DEMAND FOR MULTI- LINEAR BACKBONE OSCILLATORS
}

\author{
Georgios Baltzopoulos $^{1 *}$, Dimitrios Vamvatsikos ${ }^{2}$, Iunio Iervolino ${ }^{3}$ \\ ${ }^{1,3}$ Università degli Studi di Napoli Federico II \\ Via Claudio 21, 80125 Naples, Italy \\ georgios.baltzopoulos@unina.it, iunio.iervolino@unina.it \\ ${ }^{2}$ National Technical University of Athens \\ 9 Heroon Politechneiou, 15780 Athens, Greece \\ divamva@mail.ntua.gr
}

Keywords: pushover, directivity, incremental dynamic analysis, performance based design.

\begin{abstract}
Nonlinear static procedures, which relate the seismic demand of a structure to that of an equivalent single-degree-of-freedom (SDOF) oscillator, are well-established tools in the performance based earthquake engineering framework and have gradually found their way into modern codes for seismic design and assessment. Initially, such procedures made recourse to inelastic spectra derived for simple elastic-plastic or bilinear oscillators, but the request for demand estimates, which delve deeper into the inelastic range, shifted the trend towards investigating the seismic demand of oscillators with more complex backbone curves.

Meanwhile, the engineering relevance of near-source (NS) pulse-like ground motions has been receiving increased attention, since it has been recognized that such ground motions can induce a distinctive type of inelastic demand. Pulse-like NS ground motions are usually the result of rupture directivity, where seismic waves generated at different points along the rupture front arrive at a site at the same time, leading to a double-sided velocity pulse, which delivers most of the seismic energy. Recent research has led to a methodology being proposed for incorporating this NS effect in the implementation of nonlinear static procedures.

Both of the aforementioned lines of earthquake engineering research motivate the present study, which investigates the ductility demands imposed by pulse-like NS ground motions on SDOF oscillators who feature pinching hysteretic behavior with trilinear backbone curves. This investigation uses incremental dynamic analysis (IDA) considering a suite of one hundred and thirty pulse-like-identified ground motions. Median, as well as 16\% and $84 \%$ fractile, IDA curves are calculated, on which an analytical model is fitted. Least-squares estimates are obtained for the model parameters, which importantly include pulse period $T_{p}$. The resulting equations effectively constitute an $R-\mu-T / T_{p}$ relation for pulse-like NS motions. A potential application of this result is briefly demonstrated in an illustrative example of NS seismic demand estimation.
\end{abstract}




\section{INTRODUCTION}

Estimating the seismic demand for structures expected to respond inelastically to future earthquakes attaining a certain intensity, is one of the key issues in performance based earthquake engineering (PBEE, see for example [1]). What sets near-source (NS) seismic input apart is the fact that NS ground motions often contain significant wave pulses. In fact, the engineering relevance of NS pulse-like ground motions has been receiving increased attention during the past decades, since it has been recognized that such ground motions can be more damaging than ordinary ground motions and can induce a distinctive type of inelastic demand. The primary cause of these impulsive characteristics in NS strong ground motion is rupture forward directivity (FD). During fault rupture, shear dislocation may propagate at velocities very near to the shear wave velocity. As a result, there is a probability that, at sites aligned along the direction of rupture propagation, shear wave-fronts generated at different points along the fault arrive almost simultaneously, delivering most of the seismic energy in a single double-sided pulse registered early in the velocity recording [2], [3]. See Figure 1 for a schematic representation of this effect and an example of a velocity pulse due to FD.

Procedures relating the structural seismic demand to that of an equivalent single-degree-offreedom oscillator, collectively known as nonlinear static procedures [4], have carved their own niche in the PBEE framework and have gradually found their way into modern codes for seismic design and assessment.
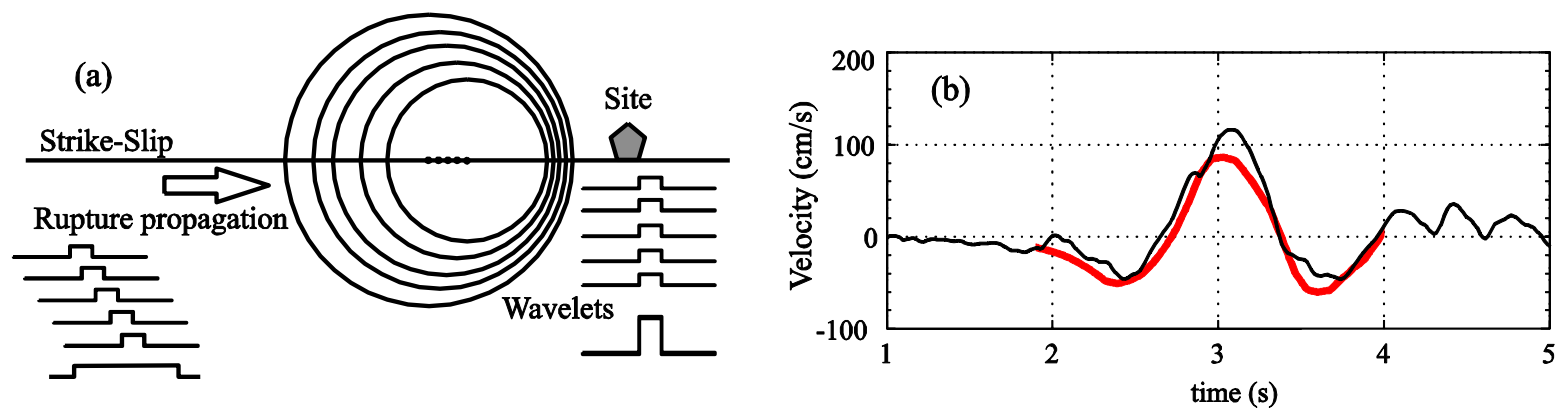

Figure 1: Snapshot of wave fronts; pictorial representation of the directivity of seismic energy adapted from [2] (a) and initial segment of the velocity time history of the fault-normal component of ground motion recorded on the left abutment of the Pacoima Dam, during the 1971 San Fernando (California) earthquake (b).

Initially, these static nonlinear procedures made recourse to inelastic spectra derived for simple elastic-perfectly-plastic or bilinear oscillators. One such procedure applicable in NS conditions has been suggested in [5]. However, the request for demand estimates that delve deeper into the inelastic range and arrive at quantifying collapse capacity (definition to follow), led researchers to also investigate the seismic demand of oscillators with more complex backbone curves such as the trilinear backbone depicted in Figure 2.

In order to fully describe this backbone curve mathematically in ductility - reduction factor normalized coordinates, three parameters are required: the slope, $\alpha_{h}$, of a plastic or hardening branch that simulates post-yield ductility and the slope, $\alpha_{c}$ and "capping point" ductility $\mu_{c}$ of a softening branch that is typical of the behavior of most structures, either brittle or ductile, that reach a maximum strength and then exhibit in-cycle degradation that leads them to negative stiffness due to strength loss. The phenomena that actually lead to negative stiffness in a real structure can include P- $\Delta$ effects and material strength degradation (often both). Negative stiffness can be encountered on the static pushover curves of many types of structures, such as braced steel frames, moment resisting steel frames, concrete frames or other types of structure that exhibit sensitivity to second order effects. 


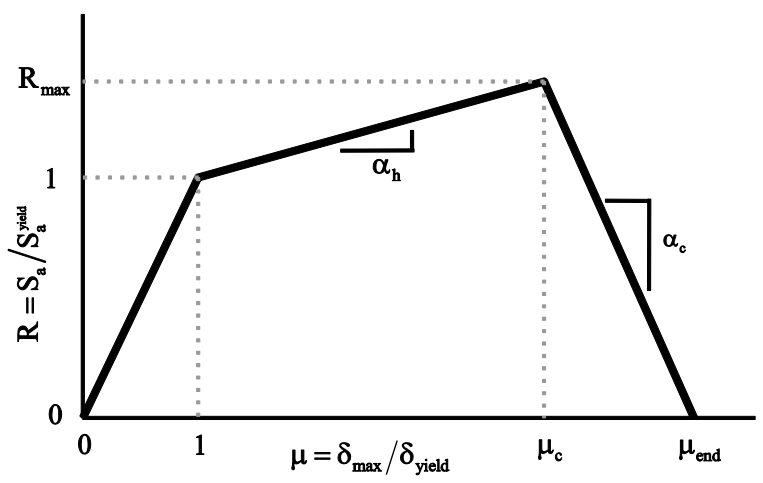

Figure 2: Representation of trilinear backbone curve in normalized coordinates (ductility $\mu$ in the abscissa and reduction factor $\mathrm{R}$ in the ordinate) and defining parameters: post-yield hardening slope $\alpha_{\mathrm{h}}$, softening branch negative slope $\alpha_{\mathrm{c}}$ and capping ductility $\mu_{\mathrm{c}}$ which separates the hardening and softening branches.

This study employs incremental dynamic analysis (IDA, [6]) in order to investigate the seismic demand of oscillators with tri-linear backbones, when subjected to NS pulse-like ground motions, with the ultimate goal of developing an analytical model. Development of this model closely follows the methodology of Vamvatsikos and Cornell [7] and uses a dataset of onehundred and thirty pulse-like ground motions exhibiting FD effects [8].

The remainder of this article is structured as follows: after a brief note on the ground motion suite employed, the methodology is laid out in detail followed by a description of the parameterfitting procedure that leads to the analytical model. Finally, an illustrative example, involving a NS design scenario, is presented to highlight the applicability of the model, followed by a brief discussion on the main conclusions of this study.

\section{DATASET OF NS PULSE-LIKE GROUND MOTIONS}

The present study employs a dataset of one-hundred and thirty pulse-like NS ground motions, whose impulsive nature is most likely related to rupture directivity. This is motivated by the fact that the stated objective is the characterization of NS structural response in relation to pulse duration $T_{p}$. Velocity pulses significantly deviating from the characteristic double-sided, earlyarriving waveform associated with directivity, may not exhibit the same type of correlation between inelastic structural response and pulse period.

Having as a starting point the dataset used in [9], the pulse identification approaches suggested in [10] and [11] were used to seek out additional directivity ground motions. This search mainly focused on more recent seismic events which provided a multitude of NS recordings, such as the Parkfield 2004 (California) event, the Darfield 2010 and Christchurch 2011 (New Zealand) events and the South Napa 2014 (California) event. During this search, some effort was made to discern those velocity pulses most likely to have been the result of directivity for eventual inclusion in this investigation. A more detailed account on the methodology employed in order to assemble this dataset, along with a complete list of the ground motion recordings and relevant metadata can be found in [8].

\section{MODELLING NEAR-SOURCE PULSE-LIKE SEISMIC DEMAND FOR TRI- LINEAR BACKBONE OSCILLATORS}

Incremental dynamic analysis is a procedure to semi-empirically estimate probabilistic seismic structural demand and capacity. This well-established procedure, typically entails a nonlinear numerical model of the structure which is subjected to a suite of ground motion records, 
all scaled at a common seismic intensity measure (IM) level. This IM level is gradually increased by applying a common scale factor simultaneously to all the records, in order to reveal the entire range of post-yield response of the structure, conditional to several IM values, up to global dynamic instability and consequent collapse.

During IDA, structural response to a single record is usually represented by plotting two scalars against each other: an IM characterizing the various scaled incarnations of the record and an engineering demand parameter (EDP) representing the amplitude of response, to obtain a single record IDA curve. Once a set of IDA curves has been collected, representing the entire suite of ground motions, it is an efficient practice to summarize the curves into sample fractile statistics. Typically sample medians, $16 \%$ and $84 \%$ fractiles are calculated [6].

IDA can be a computationally intensive procedure. This fact motivated Vamvatsikos and Cornell to develop a software tool, which provides a shortcut, at the cost of introducing some approximation in the process [7]. Having observed that summary IDA curves of SDOF systems with multi-linear backbone curves exhibit a consistent behavior in correspondence with each segment of the backbone (elastic, post-yield hardening, post-cap softening and residual strength segments, the first three represented in Figure 1), they used IDA to investigate the response of a large population of oscillators with varying backbone parameters.

Having thus mapped the behavior of many backbone shapes against a suite or ordinary ground motions, not affected by directivity, they proposed a tool, aptly named SPO2IDA, capable or reproducing the IDA curves of these SDOF systems without having to run any analysis. Essentially SPO2IDA is nothing less than a complex R- $\mu$-T relation applicable to ordinary ground motions (SPO2IDA tool available online at http://users.ntua.gr/divamva/software/spo2ida-allt.xls, last accessed April 1st, 2015).

The objective of this study is to follow in the footsteps of Vamvatsikos and Cornell [7] and employ IDA on trilinear backbone SDOF systems using a set of pulse-like records, in order to develop the equivalent of an $\mathrm{R}-\mu-\mathrm{T} / \mathrm{T}_{\mathrm{p}}$ relation appropriate for NS FD ground motions.

\subsection{Predictor variables}

A parametric model that predicts the fractile IDA curves of pulse-like FD ground motions (which will occasionally be referred to as pulse-like IDAs for brevity in the following) for SDOF oscillators featuring a generic trilinear backbone will necessarily include all the parameters that uniquely define the geometry of the backbone curve. This means $\alpha_{h}, \mu_{c}$ and $\alpha_{c}$ (see Figure 1) should all be included as explanatory variables in the model. The effect of varying these parameters on the seismic response to pulse-like ground motions has already been the object of investigation [12]. An additional variable that must be included in the model is pulse period, by virtue of its demonstrable value as a predictor for the inelastic response of this type of ground motion [9], [13]. In this case, pulse period is included as the denominator of the normalized period ratio $\mathrm{T} / \mathrm{T}_{\mathrm{p}}$, in a manner analogous to [9]. Consequently, the ground motion IM adopted for the IDAs is strength reduction factor R, defined as per Equation (1). EDP of choice for the SDOF systems is ductility $\mu$ defined as the ratio of maximum displacement to displacement at yield - Equation (2).

$$
\mathrm{R}=\frac{\mathrm{S}_{\mathrm{a}}\left(\mathrm{T}_{\mathrm{i}}=\kappa \cdot \mathrm{T}_{\mathrm{p}, \mathrm{i}}, \xi=5 \%\right)}{\mathrm{S}_{\mathrm{a}}^{\text {yield }}\left(\mathrm{T}_{\mathrm{i}}, 5 \%\right)}, \quad \kappa=\frac{\mathrm{T}}{\mathrm{T}_{\mathrm{p}}} \in[0.10,2.00]
$$




$$
\mu=\frac{\delta_{\text {max }}}{\delta_{\text {yield }}}
$$

This effectively means that IDA curves computed in this study for given values of the $T / T_{p}$ ratio, collect the responses of oscillators with different vibration periods (since, in general, every record has a different pulse duration $\mathrm{T}_{\mathrm{p}}$ associated with it) and thus only make sense as cross-sectional data when plotted in normalized $\{\mu, \mathrm{R}\}$ coordinates. This approach raises the concern that one should avoid mixing the response of very low-period oscillators, which is characterized by high ductility demands even when ordinary records are concerned, with the response of moderate-to-long period oscillators subjected to long duration pulses. To address this concern an additional restriction is imposed, that of only considering response data at each $\mathrm{T} / \mathrm{T}_{\mathrm{p}}$ cross-section for which $\mathrm{T} \geq 0.30 \mathrm{~s}$.

\subsection{Hysteretic rule}

When oscillators featuring a descending branch are concerned, it was found that a kinematic hardening hysteretic rule is not representative of how actual structures have been observed to behave during experiments [14]. With this information in mind, a peak-oriented, moderately pinching hysteresis rule developed by Ibarra and Krawinkler [15] was adopted for the present study. This hysteretic rule does not include any cyclic strength degradation, but this is considered to be of secondary importance. Strength degradation only tends to supersede the shape of the backbone in importance when severe degradation is encountered in low-period structures. However, given the range of pulse-periods associated with the NS-FD record suite employed in this study [8], the model is more oriented towards moderate to long period structures and cyclic degradation is not included in the hysteretic rule used in the analyses.

\subsection{Equivalent ductility concept}

A straightforward way of tackling the problem of modelling pulse-like IDAs could be to run a very large number of individual incremental dynamic analyses in an attempt to span the entire parameter space of $\alpha_{c}, \alpha_{h}, \mu_{c}$ and $\mathrm{T} / \mathrm{T}_{\mathrm{p}}$. However, structural responses exhibit a complicated interdependency with respect to the four parameters (backbone characteristics and normalized period), which cannot be regarded independently one from another; this means that considering all their meaningful combinations leads to a population of SDOF oscillators numbering in the thousands, and an amount of IDAs which can be hard to obtain and manage.

Fortunately, one can take advantage of the experience accumulated in [7] to drastically reduce the amount of necessary analyses. More specifically, it was found that the equivalent ductility $\mu_{\mathrm{eq}}$ concept (see Figure 3), which was introduced in the analogous study of ordinary ground motion IDAs [7], can also be employed for the case at hand. In that study Vamvatsikos and Cornell found that oscillators with a generic backbone containing both a hardening segment and negative-stiffness softening branches with coincident post-capping slope, such as those shown in Figure 3, have a very similar part of the IDA between capping ductility and the flatline. The flat-line actually develops at some point slightly prior to reaching zero strength at , which is given by Equation (3).

$$
\mu_{\text {end }}=\mu_{c}+\frac{1+\mu_{c} \cdot \alpha_{h}-\alpha_{h}}{\left|\alpha_{c}\right|}
$$




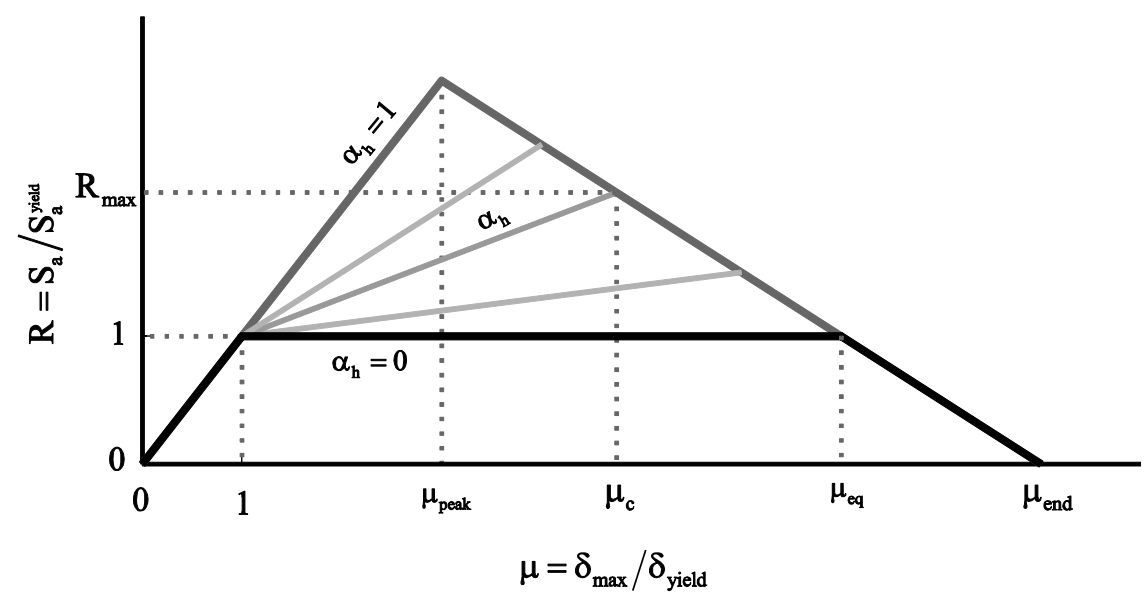

Figure 3: Schematic representation of the "equivalent ductility" $\mu_{\mathrm{eq}}$ concept.

Furthermore, flat-line height among these oscillators varies in an almost linear fashion between the two extremes marked by $\alpha_{h}=0$ and $\alpha_{h}=1$ in Figure 3. Therefore, for any tri-linear oscillator with given capping ductility $\mu_{c}$, one needs only determine ductility at maximum strength reduction factor $\mu_{\text {peak }}$, given by Equation (4) and equivalent ductility $\mu_{\text {eq }}$ where an $\alpha_{\mathrm{h}}=0$ oscillator meets the common negative branch and is given by Equation (5).

$$
\begin{gathered}
\mu_{\text {peak }}=\frac{1+\mu_{c} \cdot\left|\alpha_{c}\right|+\alpha_{h} \cdot\left(\mu_{c}-1\right)}{1+\left|\alpha_{c}\right|} \\
\mu_{\text {eq }}=\mu_{c}+\frac{\alpha_{h} \cdot\left(\mu_{c}-1\right)}{\left|\alpha_{c}\right|}
\end{gathered}
$$

As long as a comprehensive model is available for these limit cases, interpolation can be used to provide the IDA curves of the intermediate oscillators, as will be shown in a subsequent example.

\section{ANALYTICAL FORM AND FITTING OF THE MODEL}

\subsection{Bilinear oscillators with hardening post-yield behavior}

The analytical functional form selected to model the pulse-like IDA curves for bilinear oscillators with hardening (positive post-yield slope) is given by Equation (6). It is a rational function (in log-space) of ductility given reduction factor fractiles, containing a total of four parameters to be determined by fitting the model to the data.

$$
\ln \mu_{\mathrm{x} \%}=\frac{\mathrm{a}_{\mathrm{x} \%} \cdot \ln ^{2} \mathrm{R}+\mathrm{b}_{\mathrm{x} \%} \cdot \ln \mathrm{R}}{\mathrm{c}_{\mathrm{x} \%} \cdot \ln \mathrm{R}+\mathrm{d}_{\mathrm{x} \%}}, \mathrm{R} \in\left(1, \mathrm{R}_{(100-\mathrm{x}) \%}\left(\mu_{\mathrm{c}}\right)\right], \mathrm{x}=\{16,50,84\}
$$

The fit follows a two-stage procedure: the first stage entails obtaining non-linear least squares estimates of the model parameters $a_{x \%}, b_{x \%}, c_{x \%}$ and $d_{x \%}$ for each distinct backbone (uniquely characterized by $\alpha_{h}$ ), normalized period $T / T_{p}$ and $x \%$ fractile IDAs, for a total of 
nine-hundred instances of parameter estimation. Subsequently, a linear model represented by Equation (7) is fit to each of the parameters, in order to capture their dependence on the remaining variables of the problem, namely $\alpha_{h}$ and $T / T_{p}$. This second stage entails a total of twelve two-dimensional fits, since for each one of the four parameters, three fractile curves must be accommodated.

$$
a_{x \%}, b_{x \%}, c_{x \%}, d_{x \%}=\sum_{i} \theta_{x \%, i} \cdot p_{i}\left(\alpha_{h}\right) \cdot q_{i}\left(\frac{T}{T_{p}}\right), \alpha_{h} \in[0,0.8), T / T_{p} \in[0.1,2.0]
$$

The terms $p_{i}\left(\alpha_{h}\right)$ and $q_{i}\left(\frac{T}{T_{p}}\right)$ represent simple functions of the variables in parentheses. A sample of the obtained results can be seen in Figure 4, where the fitted curves for all 3 fractile $\mu_{\mathrm{x} \%} \mid \mathrm{R}$ IDA curves are plotted against the analysis results for three oscillators with increasing post-yield stiffness and for different $\mathrm{T} / \mathrm{T}_{\mathrm{p}}$ ratios. Coefficient estimates for Equation (7) can be found in [8].
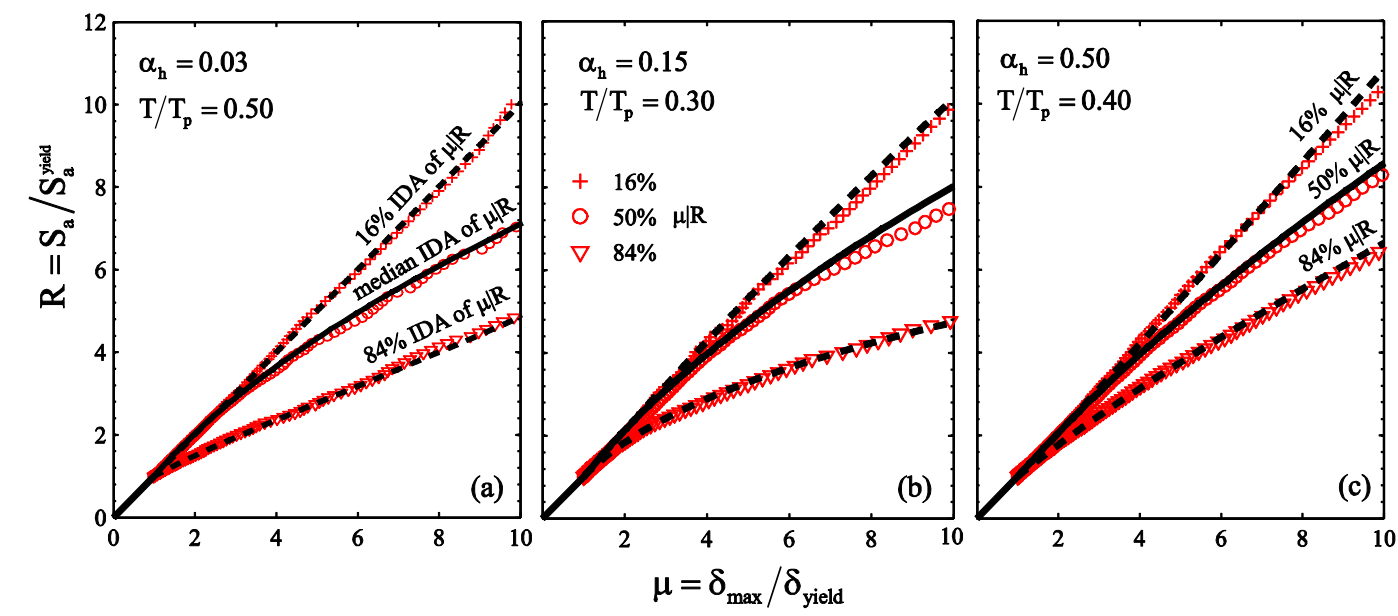

Figure 4: Comparison of the fitted model of Equation (6) with the underlying data for SDOF systems (a) with $\alpha_{\mathrm{h}}=3 \%$ at $\mathrm{T} / \mathrm{T}_{\mathrm{p}}=0.50$, (b) $\alpha_{\mathrm{h}}=15 \%$ at $\mathrm{T} / \mathrm{T}_{\mathrm{p}}=0.30$ and (c) $\alpha_{\mathrm{h}}=50 \%$ at $\mathrm{T} / \mathrm{T}_{\mathrm{p}}=0.40$.

\subsection{Bilinear oscillators with softening (negative slope) post-yield behavior}

The appearance of a softening on the backbone curve, automatically introduces the question of collapse capacity (i.e. strength reduction factor that causes dynamic instability in the oscillator) into the problem. In the trilinear backbones examined here (where no residual strength part is taken into consideration), the segment with negative post-yield slope will eventually cross the zero capacity axis at $\mu_{\text {end }}$; see Equation (4). Dynamic instability, indicated by the typical IDA flat-line will actually occur at a ductility level slightly lower than $\mu_{\text {end }}$. The height of the flat-line will be henceforth referred to as collapse capacity $\mathrm{R}_{\text {cap }}$ while the corresponding ductility will be indicated as $\mu_{\text {cap }}$ (ductility at capacity, not to be confused with capping ductility $\left.\mu_{\mathrm{c}}\right)$. 
In the case of bilinear oscillators, ascending post-yield slopes starting from close to unity and running up to (and including) the horizontal, were examined in the previous section. However, as soon as the slope of the backbone past the yielding point begins to descend, the additional variable of flat-line height $\mathrm{R}_{\text {cap }}$ must be also accounted for by the model.

Contrary to the hardening case, for which Equation (6) gives fractile $\mu$ given $R\left(\mu_{x \%} \mid R\right.$ ) IDAs, for the negative post-yield slope case it was chosen to fit a reduction factor given ductility (fractile $R_{x \%} \mid \mu$ ), model, which is given by Equation (8) and supplemented by Equation (9).

$$
\begin{gathered}
\ln \mathrm{R}_{\mathrm{x} \%}=\frac{\mathrm{a}_{\mathrm{x} \%} \cdot \ln \mu}{\ln \mu+\mathrm{b}_{\mathrm{x} \%}}, \mu \in\left(1, \mu_{\operatorname{cap}(100-\mathrm{x}) \%}\right], \quad \mathrm{x}=\{16,50,84\} \\
\mathrm{a}_{\mathrm{x} \%}, \mathrm{~b}_{\mathrm{x} \%}=\sum_{\mathrm{i}} \theta_{\mathrm{x} \%, \mathrm{i}} \cdot \mathrm{p}_{\mathrm{i}}\left(\left|\alpha_{\mathrm{c}}\right|\right) \cdot \mathrm{q}_{\mathrm{i}}\left(\frac{\mathrm{T}}{\mathrm{T}_{\mathrm{p}}}\right), \alpha_{\mathrm{c}} \in[-4.0,-0.05), \mathrm{T} / \mathrm{T}_{\mathrm{p}} \in[0.1,2.0]
\end{gathered}
$$

According to [16], the $\mu_{\mathrm{x} \%} \mid \mathrm{R}$ and $\mathrm{R}_{(100-\mathrm{x}) \%} \mid \mu$ fractile IDA curves are almost identical, even when the typical IDA properties of continuity and monotonicity are slightly violated. Therefore, collapse capacity $\mathrm{R}_{\text {cap }, \mathrm{x} \%}$ should also appear on the corresponding $\mu_{(100-\mathrm{x}) \%} \mid \mathrm{R}$ curve. The motivation behind this modeling choice lies in the prediction of collapse capacity. As can be seen in Figure 5, the tangent slope of each summary IDA curve, progressively decreases as ductility approaches $\mu_{\text {end }}$. This means that, as strength reduction factor approaches $R_{\text {cap }}$, small variations in reduction factor correspond to much greater variations in ductility.

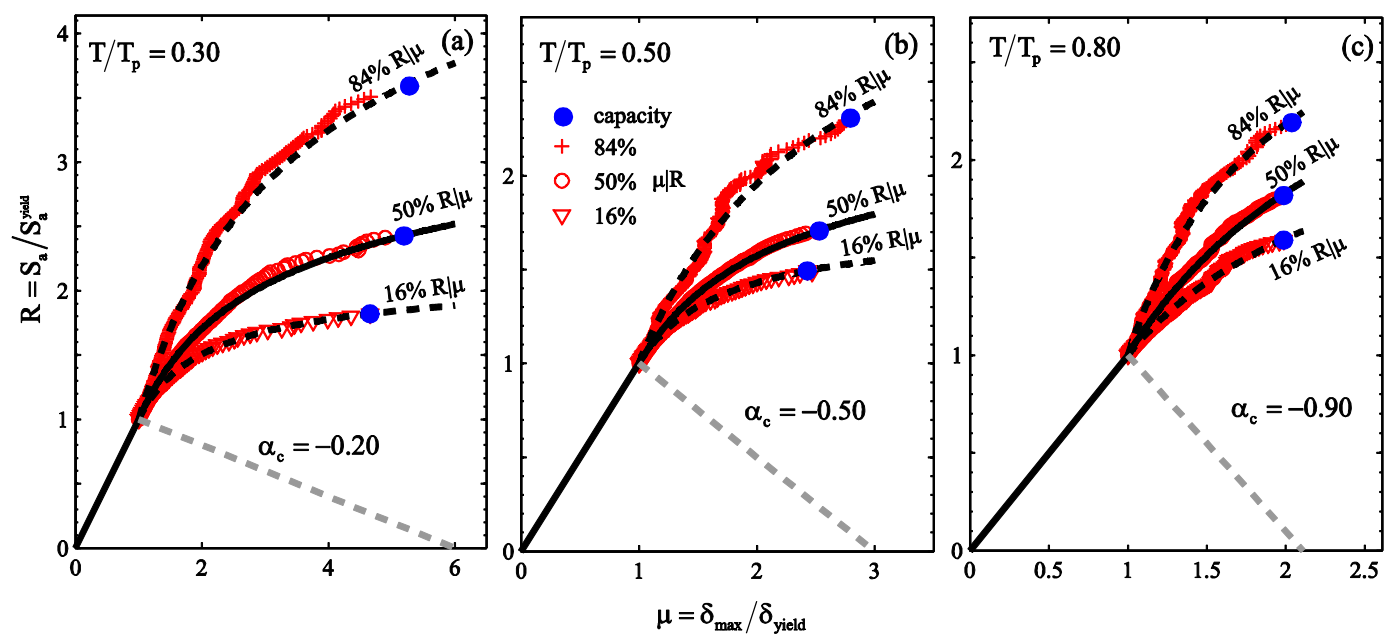

Figure 5: Model fit of Equation (8) plotted over calculated SDOF pulse-like IDAs for oscillators with (a) $\alpha_{c}=-0.20$ at $\mathrm{T} / \mathrm{T}_{\mathrm{p}}=0.30$, (b) $\alpha_{\mathrm{c}}=-0.50$ at $\mathrm{T} / \mathrm{T}_{\mathrm{p}}=0.50$ and (c) $\alpha_{\mathrm{c}}=-0.90$ at $\mathrm{T} / \mathrm{T}_{\mathrm{p}}=0.80$. Note that the fitted model has been extended past the collapse capacity point only for presentation reasons.

This observation has an important practical implication. Given a hypothetical model for $\mathrm{R}_{\mathrm{x} \%} \mid \mu$ or $\mu_{(100-\mathrm{x}) \%} \mid \mathrm{R}$ fractile IDAs with misfit (i.e., a model exactly reproducing the data) and a separate model for $\mathrm{R}_{\text {cap }}$, some inevitable misfit in the latter will cause the point of collapse not to fall exactly on the predicted IDA curve. Recalling now the observation about the tangent 
slope of the curve, it becomes apparent that a small misfit in predicted flat-line height can cause the flat-line to intersect the IDA "too early" or even unrealistically "late" (beyond $\mu_{\text {end }}$ ).

On the other hand, if one were to adopt a model that predicts ductility at collapse capacity $\left(\mu_{\text {cap }}\right)$, any fitting error would perturb the prediction along the abscissa (assuming $\mu$ is plotted on the horizontal axis as in Figure 5) resulting in negligible difference on the corresponding reduction factor. However, modelling $\mu_{\text {cap }}$ does not automatically resolve the problem; an ordinary least squares fit of Equations (8-9) does not guarantee that the $\mathrm{R}_{\mathrm{x} \%} \mid \mu$ curve passes through $\mathrm{R}_{\text {cap }}$. For this reason, the finally adopted solution is the combination of a weighted least squares fitting scheme for Equation (8) with a model for $\mu_{\text {cap }, \mathrm{x} \%}$ fractiles given by Equations (10-11).

$$
\begin{gathered}
\mu_{\text {cap } x \%}=\mu_{c}+c_{x \%} \cdot \frac{1+\alpha_{h} \cdot\left(\mu_{c}-1\right)}{\left|\alpha_{c}\right|}, \alpha_{h} \in[0,0.8), \alpha_{c} \in[-4.0,-0.05), x=\{16,50,84\} \\
c_{x \%}=\beta_{x \%} \cdot \frac{\mu_{c}-\mu_{\text {peak }}}{\mu_{\text {eq }}-\mu_{\text {peak }}}, \beta_{x \%}=\{0.85,1.00,1.05\} \text { for } x=\{16,50,84\}
\end{gathered}
$$

This concept, employs an adaptive weighting scheme when fitting Equation (8) to the data; the point of collapse capacity is given an increased weight until the fitted curve passes through this point within a prescribed tolerance on the ordinate axis (reduction factor). Essentially, the model is forced to prioritize capturing the point of collapse capacity with increased accuracy. Thus, we may consider that $\mathrm{R}_{\text {cap, } \mathrm{x} \%} \approx \mathrm{R}_{\mathrm{x} \%} \mid \mu=\mu_{\text {cap,(100-x)\% }}$ as per Equation (8), having ensured that this estimate is less susceptible to fitting error than direct modelling of the flat-line height. Coefficient estimates for Equation (9) can also be found in [8].

\section{RESULTS AND DISCUSSION}

The analytical models whose development was presented in the preceding paragraphs, can be combined to obtain a prediction for pulse-like IDAs of oscillators in procession of a fullytrilinear backbone curve. The empirical principles underlying this approach have already been either detailed or alluded to in the previous sections. What remains is an illustration of their application. Such an application is shown in Figure 6, for an oscillator characterized by backbone parameters $\alpha_{\mathrm{h}}=0.20, \mu_{\mathrm{c}}=6$ and $\alpha_{\mathrm{c}}=-0.50$. In order to obtain this composite prediction, Equation (6) is implemented for as long as , with each segment culminating at reduction factor levels indicated as in Figure 6. Subsequently, the negative slope part is modeled, by using Equation (8) for an interval of ductility . This segment is adjusted in height at the intersection with the previous model, so that the points will belong to both segments, in the interest of continuity. 


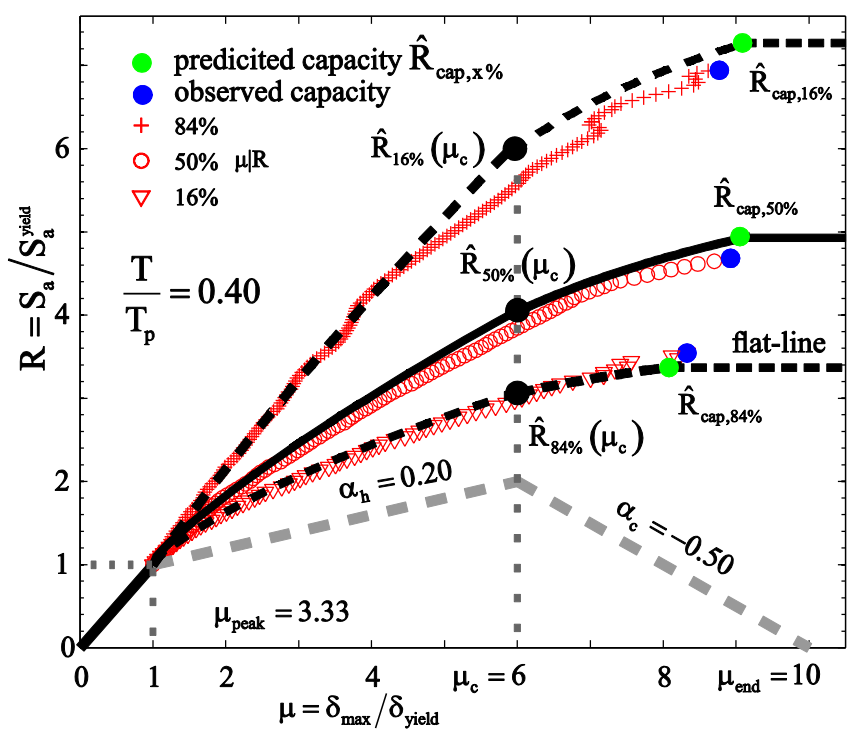

Figure 6: Model prediction of the fractile pulse-like IDAs for a trilinear backbone oscillator $\left(\alpha_{\mathrm{h}}=0.20\right.$,

$$
\alpha_{\mathrm{c}}=-0.50 \text { and } \mu_{\mathrm{c}}=6 \text { ) at } \mathrm{T} / \mathrm{T}_{\mathrm{p}}=0.40 \text {. }
$$

\section{ILLUSTRATIVE APPLICATION}

Despite the fact that the model provides output in the form of fractile IDA curves, these should not be employed to directly estimate the probabilistic distribution of EDP given IM. The reason behind this is the fact that the IDA curves refer to a given $T / T_{p}$ ratio, rather than a specific structure. In fact, the model acts like an $\mathrm{R}-\mu-\mathrm{T} / \mathrm{T}_{\mathrm{p}}$ relation, which must be combined with site-specific information on pulse period and likelihood of directivity. As such, it could be employed in a manner analogous to the methodology of [5] in order to render a static non-linear procedure, for example the capacity spectrum method [17], applicable in NS conditions.

An illustrative example of this concept is presented in Figure 7. In the first panel, Figure 7(a), the median SPO2IDA ordinary prediction for a bilinear oscillator characterized by a $\mathrm{T}=1$.0s period of natural vibration, post-yield hardening slope $\alpha_{\mathrm{h}}=0.20$ and spectral acceleration at yield $\mathrm{S}_{\mathrm{a}}^{\text {yield }}=0.10 \mathrm{~g}$ is compared against various median IDAs which incorporate pulselike effects in both arbitrary and systematic fashion.

The median IDAs used for the comparison, consist of one curve obtained by running IDA for a set of thirty randomly selected pulse-like ground motions (with an average pulse period $\overline{\mathrm{T}}_{\mathrm{p}}=1.62 \mathrm{~s}$ ), another obtained by means of Equation (6) for $\mathrm{T} / \mathrm{T}_{\mathrm{p}}=0.40$ and a third curve obtained by integrating Equation (6) over various potential pulse periods from a site-specific NS design scenario (to follow). A final comparison is made with an IDA curve that accounts for both the ordinary and pulse-like component of seismic demand at the site, each weighted by its respective likelihood.

The NS scenario under consideration refers to a site being affected by a seismic source characterized by a nearly vertical strike-slip mechanism, with seismicity governed by an M7 characteristic earthquake model and maximum rupture area of $1330 \mathrm{~km}^{2}$. The site is $5 \mathrm{~km}$ distant from the horizontal projection of the assumed fault plane and therefore some directivity effects are to be expected (Figure 8). 


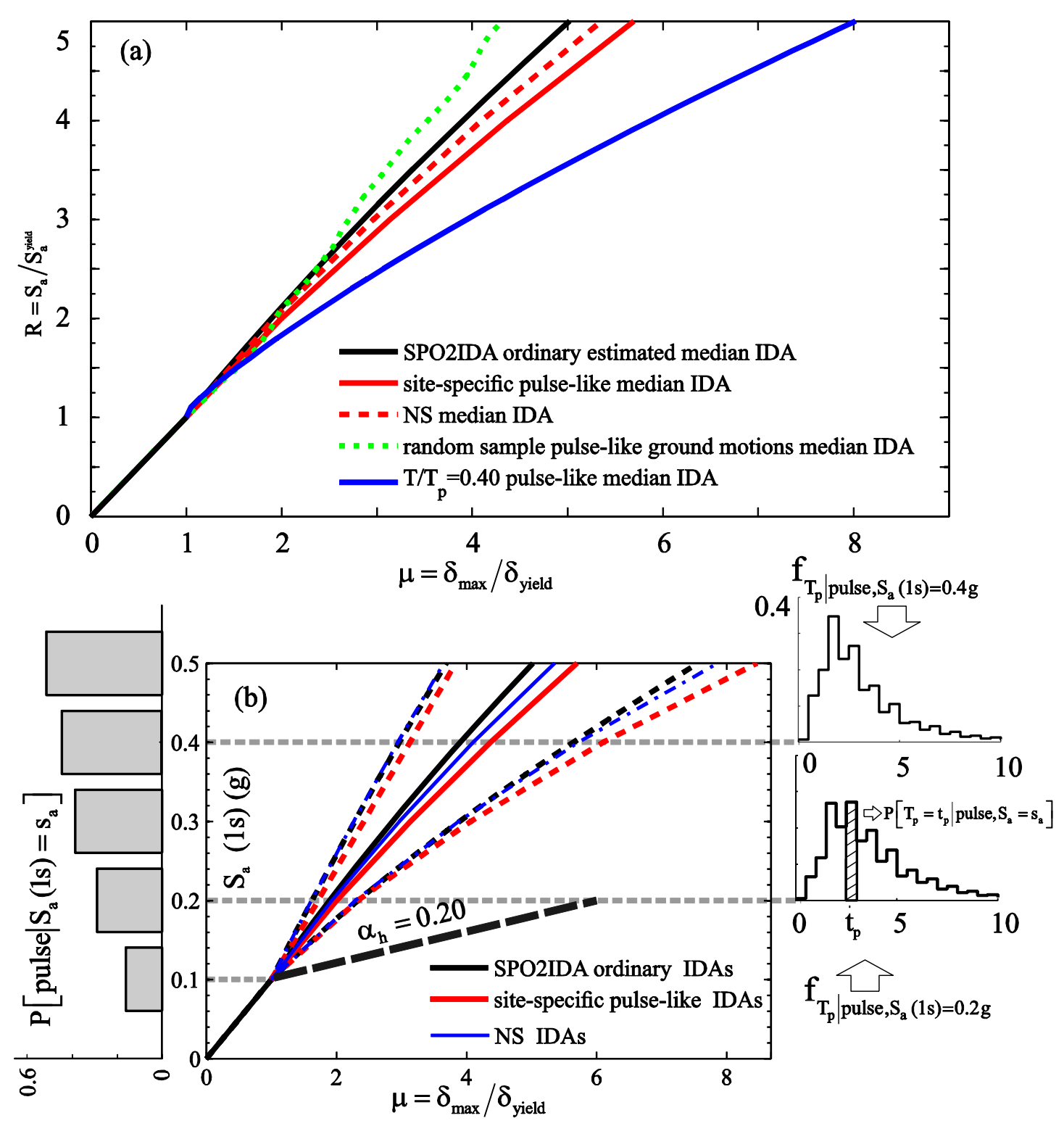

Figure 7: (a) Ordinary SPO2IDA median prediction for a bilinear oscillator with vibration period T=1.0s, postyield hardening slope $\alpha_{h}=0.10$ and spectral acceleration at yield $S_{a}^{\text {yield }}=0.10 \mathrm{~g}$ compared with curves incorporating pulse-like effects in both arbitrary and systematic fashion. (b) Information obtained from site-specific (see

Figure 8) NS hazard incorporated into the pulse-like IDA model to obtain site-specific IDA curves.

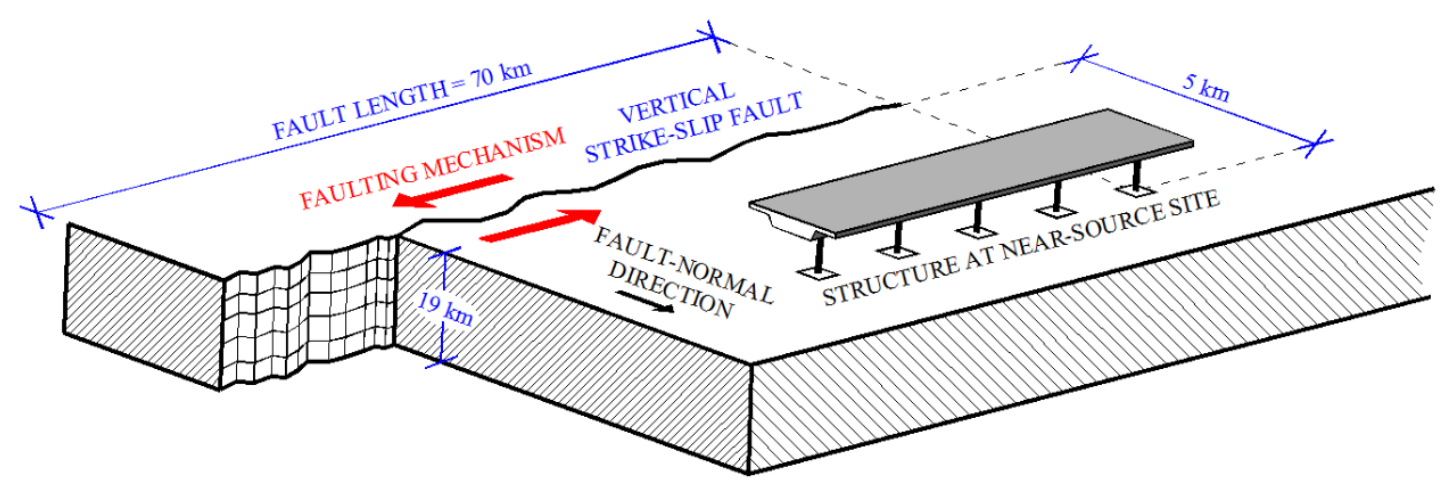

Figure 8: Schematic representation of NS design scenario used in the illustrative example. 
NS hazard at the site expressed in terms of spectral acceleration at the oscillator's period was disaggregated for various values of chosen to translate into reduction factors. Thus, the conditional probability density functions of pulse period are obtained at each stripe of reduction factor (the interested reader is referred to [18] and [19] for a detailed treatment of the methodology involved in these NS probabilistic seismic hazard analysis calculations).

This information is incorporated into Equation (6) by assuming that ductility given demand follows a lognormal distribution, leading to Equation (12), where the abbreviated notation is used to indicate the conditional probability mass, resulting from discretizing the random variables involved (see Figure $7 b$ ) in order to avoid integral notation when writing the law of conditional expectation.

$$
\mathrm{E}[\ln \mu \mid \mathrm{R}, \text { pulse }] \approx \sum_{\mathrm{i}} \ln \mu_{50 \%}\left(\mathrm{R}, \mathrm{T} / \mathrm{t}_{\mathrm{p}, \mathrm{i}}\right) \cdot \mathrm{P}_{\mathrm{t}_{\mathrm{p}, \mathrm{i}}}
$$

Under the same assumption of log-normality, the law of conditional variance can be written as in Equation (13), where the notation $\operatorname{Var}[\cdot]$ indicates the variance operator. It should be mentioned that in order to maintain a more parsimonious notation, the condition $\mathrm{S}_{\mathrm{a}}(\mathrm{T})=\mathrm{s}_{\mathrm{a}}$, which holds for all expected values and variances, is replaced by strength reduction factor $\mathrm{R}$ in the following equations (for the specific structure, yield force is known).

$$
\begin{aligned}
& \operatorname{Var}[\ln \mu \mid \mathrm{R}, \text { pulse }] \approx \sum_{\mathrm{i}} \operatorname{Var}\left[\ln \mu \mid \mathrm{R}, \mathrm{T} / \mathrm{T}_{\mathrm{p}}\right] \cdot \mathrm{P}_{\mathrm{t}_{\mathrm{p}, \mathrm{i}}}+ \\
& +\sum_{\mathrm{i}}\left[\mathrm{E}[\ln \mu \mid \mathrm{R}, \text { pulse }]-\ln \mu_{50 \%}\left(\mathrm{R}, \mathrm{T} / \mathrm{t}_{\mathrm{p}, \mathrm{i}}\right)\right]^{2} \cdot \mathrm{P}_{\mathrm{t}_{\mathrm{p}, \mathrm{i}}}
\end{aligned}
$$

Note that in Equation (13) $\operatorname{Var}\left[\ln \mu \mid \mathrm{R}, \mathrm{T} / \mathrm{T}_{\mathrm{p}}\right]=1 / 4 \cdot\left[\ln \mu_{84 \%}\left(\mathrm{R}, \mathrm{T} / \mathrm{t}_{\mathrm{p}, \mathrm{i}}\right)-\ln \mu_{16 \%}\left(\mathrm{R}, \mathrm{T} / \mathrm{t}_{\mathrm{p}, \mathrm{i}}\right)\right]^{2}$ due to the log-normality assumption invoked earlier. This procedure and its end result (in terms of both mean and variance), are illustrated in the second panel, Figure 7(b). To the right of the IDA curves plot, the conditional densities of pulse period for two stripes of $S_{a}(1 s)=0.2 \mathrm{~g}$ and $\mathrm{S}_{\mathrm{a}}(1 \mathrm{~s})=0.4 \mathrm{~g}$ are shown, while on the left of the vertical axis, the probabilities of pulse occurrence being causal of $\mathrm{S}_{\mathrm{a}}(1 \mathrm{~s})=\mathrm{s}_{\mathrm{a}}, \mathrm{P}\left[\right.$ pulse $\left.\mid \mathrm{S}_{\mathrm{a}}(1 \mathrm{~s})=\mathrm{s}_{\mathrm{a}}\right]$ are plotted, which are also the result of NS hazard disaggregation.

The final step of the procedure consists of accounting for both cases, i.e. occurrence of directivity pulse and absence thereof, in a single set of IDA curves. As already mentioned, the SPO2IDA prediction serves as an estimate of the ordinary component of seismic demand in this example. Applying the laws of conditional expectation and variance one more time, Equations (14) and (15) are obtained, where $\mathrm{E}[\ln \mu \mid \mathrm{R}$, nopulse $]$ is the logarithm of the median SPO2IDA prediction and the corresponding variance is estimated as $\operatorname{Var}[\ln \mu \mid R$, nopulse $]=$ $=1 / 4 \cdot\left[\ln \mu_{\mathrm{SPO} 2 \mathrm{IDA}, 84 \%}(\mathrm{R})-\ln \mu_{\mathrm{SPO} 2 \mathrm{IDA}, 16 \%}(\mathrm{R})\right]^{2}$. These results lead to the curves labeled "NS IDAs" in Figure 5.7(b).

$$
\mathrm{E}[\ln \mu \mid \mathrm{R}]=\mathrm{E}[\ln \mu \mid \mathrm{R}, \text { pulse }] \cdot \mathrm{P}[\text { pulse } \mid \mathrm{R}]+\mathrm{E}[\ln \mu \mid \mathrm{R}, \text { nopulse }] \cdot(1-\mathrm{P}[\text { pulse } \mid \mathrm{R}])
$$




$$
\begin{aligned}
& \operatorname{Var}[\ln \mu \mid \mathrm{R}]= \\
& =\operatorname{Var}[\ln \mu \mid \mathrm{R}, \text { pulse }] \cdot \mathrm{P}[\text { pulse } \mid \mathrm{R}]+\operatorname{Var}[\ln \mu \mid \mathrm{R}, \text { nopulse }] \cdot(1-\mathrm{P}[\text { pulse } \mid \mathrm{R}])+ \\
& +(\mathrm{E}[\ln \mu \mid \mathrm{R}, \text { pulse }]-\mathrm{E}[\ln \mu \mid \mathrm{R}])^{2} \cdot \mathrm{P}[\text { pulse } \mid \mathrm{R}]+ \\
& +(\mathrm{E}[\ln \mu \mid \mathrm{R}, \text { nopulse }]-\mathrm{E}[\ln \mu \mid \mathrm{R}])^{2} \cdot(1-\mathrm{P}[\text { pulse } \mid \mathrm{R}])
\end{aligned}
$$

\section{CONCLUSIONS}

The present study saw the use of IDA to investigate the response of oscillators with trilinear backbone curves to NS pulse-like ground motions. To this end, an analytical model was developed for the prediction of pulse-like IDA curves. This model includes the pulse period as a predictor variable and captures central tendency and dispersion of NS pulse-like seismic demand and capacity.

Overall, it can be observed that the assumption of a specific pulse period being considered representative across all scale factors of the IDA can lead to overestimation of NS seismic demand, when said pulse period corresponds to a fraction of structural period associated with aggressive NS FD ground motions. On the other hand, a random sample of pulse-like ground motions, where $T_{p}$ is not accounted for explicitly, can result in demand which is even less than the ordinary estimate (albeit said ordinary estimate corresponds to an analytical model).

Finally, consideration of $\mathrm{T}_{\mathrm{p}}$ in manner consistent with NS hazard, can result in seismic demand which supersedes the ordinary estimate, when site-to-source geometry renders the site prone to FD effects. In the provided example, the NS median seismic demand represented by the corresponding IDA curve shows a trend of increasing detachment from the ordinary curve as $\mathrm{S}_{\mathrm{a}}$ levels increase. The example further demonstrates that it is possible to integrate the model into the SPO2IDA tool, in order to extend applicability of the latter into the domain of NS demand. However, such integration will require that the model be extended to also cover a residual strength segment on the backbone curve, as well as lower period $(0.10 \mathrm{~s}<\mathrm{T}<0.30 \mathrm{~s})$ oscillators, in order to match the applicability range of the existing SPO2IDA tool.

\section{ACKNOWLEDGEMENTS}

The study presented in this paper was developed partially within the activities of Rete dei Laboratori Universitari di Ingegneria Sismica (ReLUIS) for the research program funded by the Dipartimento della Protezione Civile (2014-2018) and in part within the AXA-DiSt (Dipartimento di Strutture per l'Ingegneria e l'Architettura) 2014-2017 research program, funded by AXA-Matrix Risk Consultants, Milan, Italy.

\section{REFERENCES}

[1] H. Krawinkler, E. Miranda, Performance-Based Earthquake Engineering, In: Earthquake Engineering: From Engineering Seismology to Performance-Based Engineering, eds. Y. Bozorgina, V.V. Bertero, CRC Press, FL, 2004.

[2] P.J. Singh, Earthquake Ground Motions: Implications for Designing Structures and Reconciling Structural Damage. Earthquake Spectra, 1(2), 239-270, 1985. 
[3] P.G. Somerville, N.F. Smith, R.W. Graves, N.A. Abrahamson. Modification of empirical strong ground motion attenuation relations to include the amplitude and duration effects of rupture directivity. Seismol Res Lett, 68, 199-222, 1997.

[4] E. Kalkan, S.K. Kunnath, Assessment of current nonlinear static procedures for seismic evaluation of buildings. Eng Struct, 29, 305-316, 2007.

[5] G. Baltzopoulos, E. Chioccarelli, I.Iervolino, The displacement coefficient method in near-source conditions. Earthquake Engng Struct. Dyn, DOI: 10.1002/eqe.2497, 2014.

[6] D. Vamvatsikos, C.A. Cornell, Incremental dynamic analysis. Earthquake Engng Struct. Dyn, 31, 491-514, 2002.

[7] D. Vamvatsikos, C.A. Cornell, Direct estimation of the seismic demand and capacity of oscillators with multi-linear static pushovers through IDA. Earthquake Engng Struct. Dyn, 35, 1097-1117, 2006

[8] G. Baltzopoulos, Structural performance evaluation in near-source conditions, $\mathrm{PhD}$ Thesis, Doctorate program in Seismic Risk, XXVII cycle, Advisor I. Iervolino, Università degli Studi di Napoli Federico II, Naples, Italy, 2015. http://wpage.unina.it/iuniervo/doc_en/Students.html

[9] I. Iervolino, E. Chioccarelli, G. Baltzopoulos, Inelastic Displacement Ratio of NearSource Pulse-like Ground Motions. Earthquake Engng Struct Dyn, 41, 2351-2357, 2012.

[10] J.W. Baker, Quantitative Classification of Near-Fault Ground Motions Using Wavelet Analysis. Bulletin of the Seismological Society of America, 97(5), 1486-1501, 2007.

[11] S.K. Shahi, J.W. Baker, An efficient algorithm to identify strong velocity pulses in multicomponent ground motions. Bulletin of the Seismological Society of America, 104(5), 2456-2466, 2014.

[12] V. Dimakopoulou, M. Fragiadaki, C. Spyrakos, Influence of modeling parameters on the response of degrading systems to near-field ground motions. Eng Struct, 53, 10-24, 2013.

[13] S. Akkar, U. Yazgan, P. Gülkan, Deformation limits for simple non-degrading systems subjected to near-fault ground motions. Proc 13 ${ }^{\text {th }}$ World Conf Earthq Eng, Vancouver BC, Canada, Paper no. 2276, 2004.

[14] M. Rahnama, H. Krawinkler, Effects of soft soils and hysteresis model on seismic demands. Report No. 108, The John A.Blume Earthquake Engineering Center, Stanford University, Stanford CA, 1993.

[15] L.F. Ibarra, H. Krawikler. Global Collapse of Frame Structures under Seismic Excitations. Report No.152, The John A. Blume Earthquake Engineering Center, Dpt. of Civil and Environmental Engineering, Stanford University, Stanford CA, 2005.

[16] D. Vamvatsikos, C.A. Cornell. Applied incremental dynamic analysis. Earthquake Spectra, 20(2), 523-553, 2004.

[17] P. Fajfar, Capacity spectrum method based on inelastic spectra. Earthquake Engng Struct. Dyn, 28, 979-993, 1999.

[18] E. Chioccarelli, I. Iervolino, Near-source seismic hazard and design scenarios. Earthquake Engng \& Struct Dyn, 42, 603-622, 2013.

[19] P. Tothong, C.A. Cornell, J.W. Baker. Explicit directivity-pulse inclusion in probabilistic seismic hazard analysis. Earthq Spectra, 23, 867-891, 2007. 